\title{
A REMARKABLE HUMAN LOWER JAW FROM PERU
}

\section{GEORGE GRANT MACCURDY \\ Yale University}

Among the specimens gathered by the Yale Peruvian Expeditions of 1914 and 1915, one human lower jaw belongs to a type so distinet as to demand more than a passing notice. The caves explored by the expeditions were all in the Highlands to the northwest of Cuzco. The most fruitful single site was the big cave near the ruins of Paucarcancha, at an elevation of 10,000 feet and near the junction of the Rio Quesca with the Rio Pampaccahuana.

From this one cave were gathered bones belonging to at least 200 individuals. Among the bones, crania and femora predominate. The crania number 192, counting those in a fragmentary condition and those of children. Very few of the crania were accompanied by their respective lower jaws. On the other hand there are scores of lower jaws that cannot be fitted to any of the crania. Among the odd lot of lower jaws was the one in question, which presumably belonged to a male. For the sake of comparison this lower jaw has been photographed with a male lower jaw of the usual size and shape from a cave at Huaracondo, about midway between Cuzco and Paucarcancha, as seen in figures 1 and 2, the lower jaw from Paucarcancha being the one at the bottom in each figure.

Although very small and narrow, the lower jaw is of robust build. The bicondylar breadth $(10 \mathrm{~cm}$.) is too small for even the smallest cranium brought back by the Expeditions, and the smallest cranium has a capacity of only $1,020 \mathrm{ccm}$. On the other hand the breadth of the ascending ramus $(3.7 \mathrm{~cm}$.) is as large as that of any other lower jaw in the entire collection from the highlands of Peru. In fact only three other lower jaws, all of them belonging to males, approach it in this respect. The ascending ramus is remarkab'e also for the straightness of its anterior margin.

In the collection taken as a whole, the coronoid process is almost without exception higher than the condyloid. In this specimen the reverse is true and the sigmoid notch is very shallow. The bigonial diameter

AMr. J. Pays. ANtzrop., Vol. V. No. 1 
PLATE I

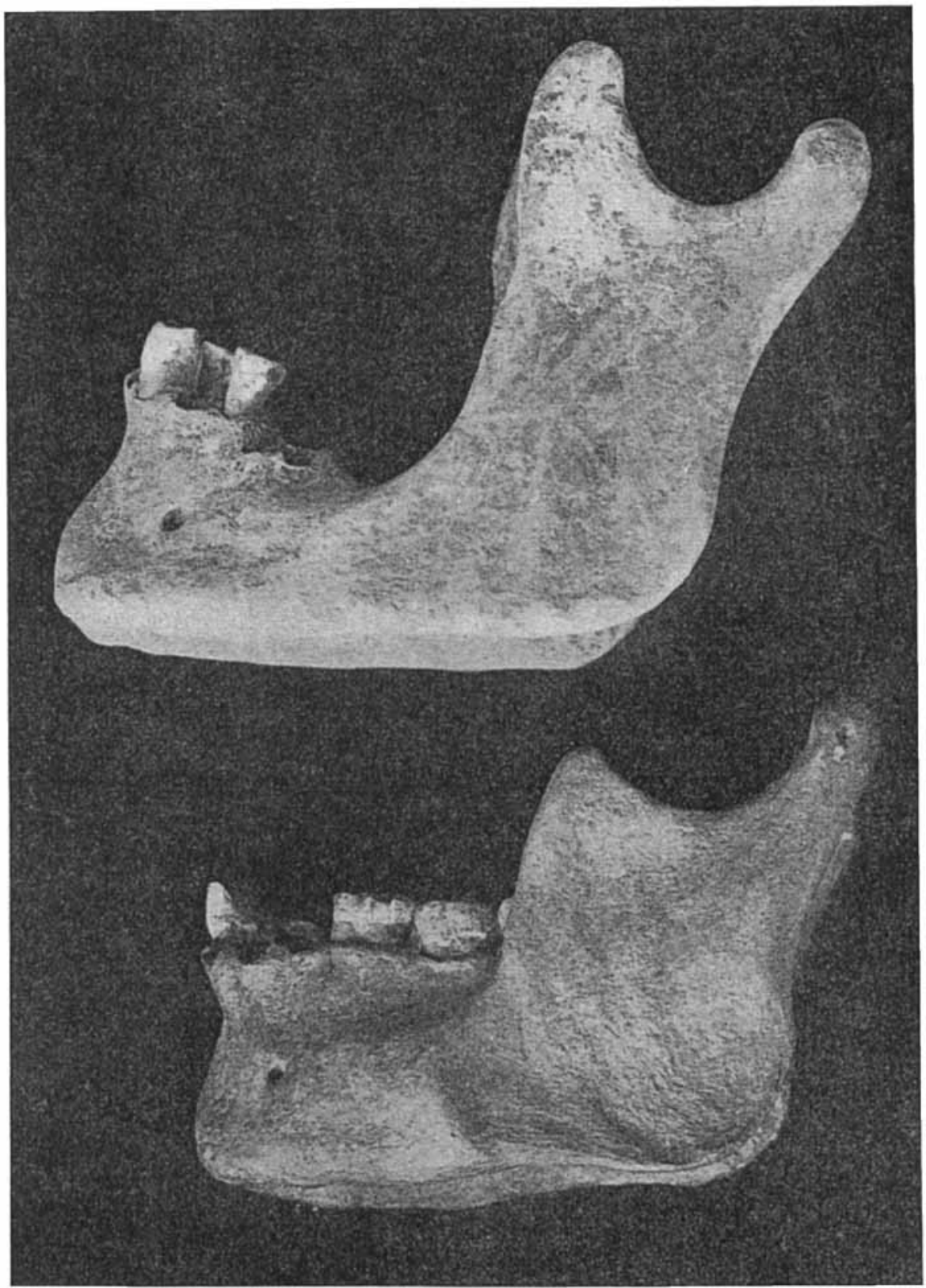

Upper: Lower Jaw of Paucarcancha

Lower: Lower Jaw of Huaracondo 
PLATE II

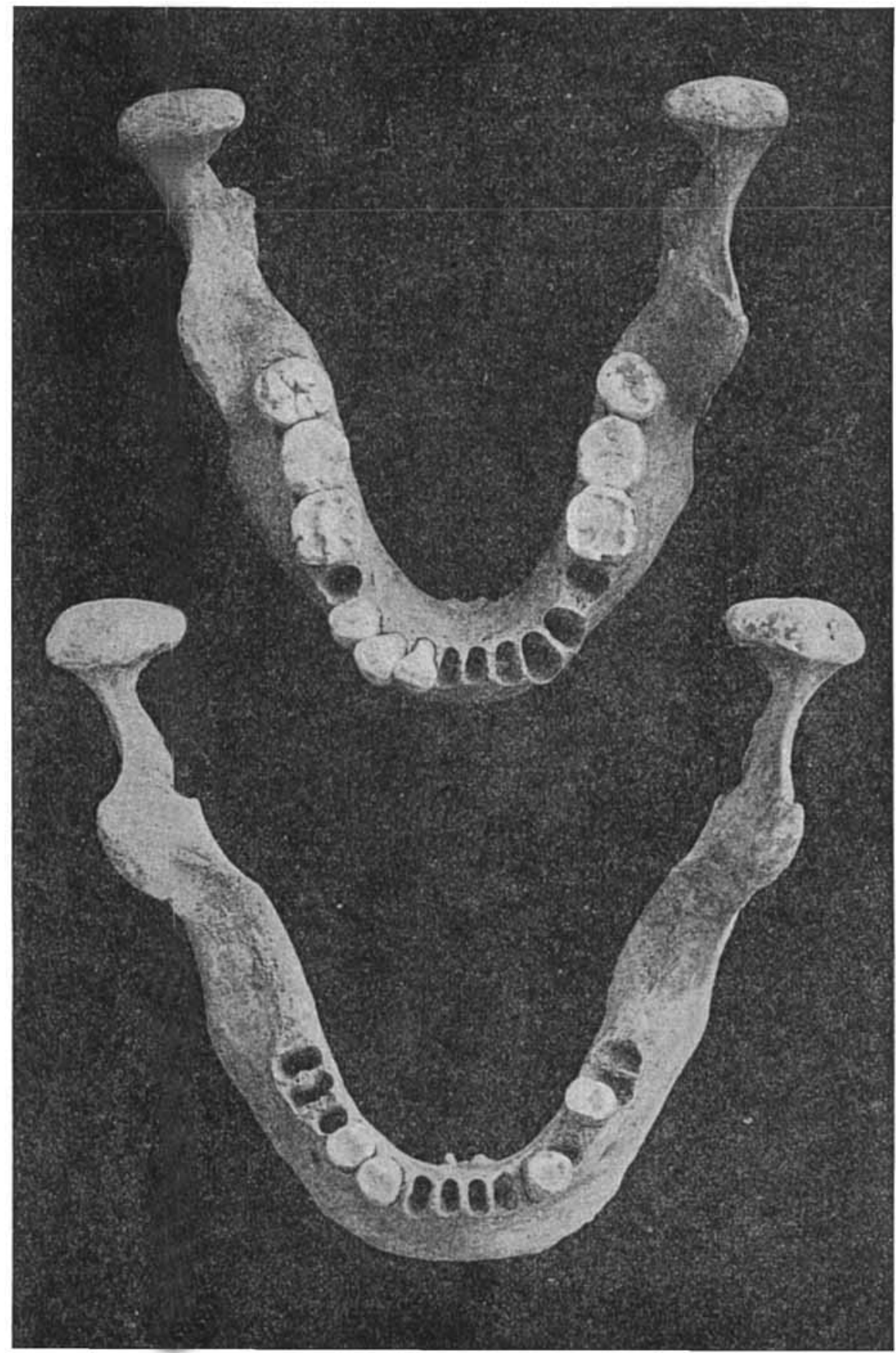

Upper: Lower Jaw of Huaracondo

Lower: Lower Jaw of Paucarcancha 
measures only $7.1 \mathrm{~cm}$. The thickness of the horizontal ramus at the level of the second molars is exaggerated $(1.8 \mathrm{~cm}$.) on account of the prominences immediately in front of the anterior limits of the masseter muscles. The spina mentalis is but feebly developed.

There are sixteen teeth, all of which were in situ at the time of decease and only one of which shows any sign of decay. The third molars are well developed and only slightly worn. The wearing of the first molars is much more pronounced, pointing to an age for the individual of some forty years.

The nearest approach to this lower jaw is found in another odd lot of specimens, also from Paucarcancha. It, however, lacks the ascending ramus. In all respects it is less robust than the previous example and probably belongs to a female of the same or a kindred type.

Had such a lower jaw as the one here figured been found in some ancient cave or rock shelter, or in diluvial deposits, it would in all probability have been hailed as the fitting representative of a new species of the genus Homo. 